\title{
OBTENÇÃO DE ÉSTERES ETILÍCOS SOB PRESSÃO A PARTIR DO ÓLEO BRUTO DE MACAÚBA
}

\author{
G.K. SOUZA ${ }^{1}$, T. L. B. PASA ${ }^{1}$, O.A.A. SANTOS ${ }^{1}$, N.C. PEREIRA ${ }^{1}$ \\ ${ }^{1}$ Universidade Estadual de Maringá, Departamento de Engenharia Química \\ E-mail para contato: gredsonkeiff@hotmail.com
}

\begin{abstract}
RESUMO - Os combustíveis derivados de petróleo foram as principais fontes de energia no último século. A crise global de combustível fósseis em 1970 conscientizou muitos países de sua vulnerabilidade e escassez. Tem-se voltado então para o desenvolvimento de processos para produção de combustíveis alternativos. O biodiesel é uma alternativa essencial para atender à crescente demanda energética de forma sustentável. Este trabalho teve como objetivo a obtenção ésteres etílicos a partir do óleo bruto de macaúba (Acrocomia Aculeata) com teor elevado de ácidos graxos livres. A fim de verificar a melhor condição na reação de esterificação, utilizou-se um planejamento fatorial $2^{3}$ e a metodologia de superfície de resposta. Nas reações de síntese, as variáveis estudadas foram: Temperatura, Razão Molar etanol:óleo e percentagem de Catalisador em relação a massa de óleo. Os éteres foram quantificados por cromatografia em fase gasosa. Foram obtidos valores de conversão superiores a $90 \%$ em ésteres etílicos.
\end{abstract}

\section{INTRODUÇÃO}

A sociedade em que vivemos é altamente dependente da energia fóssil, assim, fontes como petróleo, carvão e gás natural (SARKAR, 2011). Iniciam-se grandes mudanças na produção e utilização de biodiesel no Brasil e a expectativa é que o país seja um dos principais produtores e consumidores de biocombustíveis do mundo, devido a grande vantagem em relação aos outros países que já produzem biodiesel, que é a sua biodiversidade (DANTAS et al., 2011; PADULA et al., 2012;).

A produção convencional de biodiesel comercial é baseada na utilização de culturas energéticas comestíveis como o óleo de soja, canola, coco e de palma (Ma \& Hanna, 1999; LIM et al., 2010). Buscam-se matérias primas que não seja competitiva com alimentos, a oleaginosa macaúba é altamente produtiva e sua composição confere ótimas características para a produção de biodiesel (BANDEIRA, 2001).

O fruto de Macaúba e constituído por duas fontes de óleo: polpa e amêndoa, e todo fruto é aproveitável - casca, polpa, castanha e amêndoa (CARGNIN et al., 2008). Dentre os diversos óleos vegetais, o óleo de macaúba representa uma alternativa promissora (Azevedo Filho et al., 2012). Sua capacidade de produção de óleo vegetal pode chegar a quatro mil litros por hectare 
por ano, sendo que por meio de plantios racionais e de programas de melhoramento este valor pode aumentar consideravelmente (NUCCI et al., 2008), pode-se chegar a uma produção de óleo vegetal de $6.000 \mathrm{~kg}$ de óleo por hectare (SILVA e ANDRADE, 2011).

Este trabalho teve como objetivo obter ésteres etílicos por catálise ácida a partir do óleo da polpa da macaúba. Utilizar planejamento fatorial para avaliar a influência da temperatura, catalisador e razão molar (RM) óleo:álcool na conversão do óleo em ésteres, determinar a melhor condição reacional por meio da análise dos resultados obtidos pelos gráficos de superfície de resposta.

\section{MATERIAIS E MÉTODOS}

Nos experimentos para a obtenção de ésteres foi utilizado o óleo da polpa (mesocarpo) de macaúba pertencente à família Arecaceae, a espécie Acrocomia aculeata (Jacq.) Lodd. Ec Mart. O óleo foi obtido da Associação dos Pequenos Produtores de Riacho Dantas de Monte Claros MG. O qual suas características físico-químicas foram determinadas conforme a metodologia oficial AOCS (American Oil Chemists' Society).

Neste trabalho, foram avaliados três variáveis, catalisador (Cat), temperatura (T) e (RM) álcool:óleo, utilizando um planejamento fatorial $2^{3}$. Conforme mostra a Tabela 1.

Tabela 1 - Níveis do planejamento fatorial DCCR

\begin{tabular}{llllll}
\hline Variáveis/Níveis & $-1,68$ & -1 & 0 & +1 & $+1,68$ \\
\hline Catalisador & 0,5 & 0,7 & 1 & 1,3 & 1,5 \\
Temperatura $\left({ }^{\circ} \mathrm{C}\right)$ & 90 & 96 & 105 & 113,9 & 120 \\
RM etanol:óleo & $4: 1$ & $5,6: 1$ & $8: 1$ & $10,3: 1$ & $12: 1$ \\
\hline
\end{tabular}

\subsection{Obtenção Dos Ésteres Etílicos}

Os experimentos foram realizados em escala laboratorial, para a obtenção dos ésteres etílicos a partir do óleo da polpa da macaúba. Na reação de esterificação, foram utilizados etanol etílico anidro $99,8 \%$, ácido sulfúrico $\left(\mathrm{H}_{2} \mathrm{SO}_{4}\right)$ marca Sigma-Aldrich como catalisador, sendo a quantidade adicionada calculada sempre em relação à massa do óleo conforme Freedman et al., (1984). Foi utilizado a metodologia de superfície de resposta para que a melhor condição seja determinada. Os parâmetros definidos tem uma resposta em conversão em ésteres. Foi utilizado um reator PARR 4843, sob pressão e agitação constante de 70 psi e 350 rpm respectivamente.

Após o termino da reação, a mistura reacional foi submetida a um evaporador rotativo marca Fisatom, modelo 803. Ligado a uma bomba hidro vácuo sob vácuo de $600 \mathrm{mmHg}$, e temperatura do banho a $60^{\circ} \mathrm{C}$ para a recuperação do álcool excedente. A separação dos éteres etílicos e da água foi realizada por decantação. 
Após a decantação e separação, a fase superior, contendo os ésteres etílicos, foi adicionada água saturada de $\mathrm{CaCO}_{3}$ para a neutralização do ácido sulfúrico. $\mathrm{Na}$ etapa de purificação dos ésteres etílicos foram feitas lavagens com água destilada a $65^{\circ} \mathrm{C}$. Para eliminar a umidade as amostras foram submetidas em um evaporador rotativo a $75^{\circ} \mathrm{C}$.

Para as análises dos ésteres, foi utilizado um cromatografo da marca Varian, modelo CP 3800, com detector de ionização de chama (DIC), contendo uma coluna capilar específica para separação de ésteres (BP - X70 - SGE) de $30 \mathrm{~m}$ x 0,25 mm. Hélio foi utilizado como gás de arraste, numa razão split de 1:10. A análise foi realizada com programação de temperatura da coluna, iniciada a $110^{\circ} \mathrm{C}$, com aquecimento até $160^{\circ} \mathrm{C}$ a $8 \mathrm{C} / \mathrm{min}$ e $230^{\circ} \mathrm{C}$ a $3,5^{\circ} \mathrm{C} / \mathrm{min}$. A temperatura do detector foi mantida em $220^{\circ} \mathrm{C}$ e a do injetor em $260^{\circ} \mathrm{C}$.

Os componentes da amostra analisada foram identificados por meio da comparação dos tempos de retenção na coluna com os tempos de retenção de uma amostra padrão. Foi utilizado um FAME Mix (fatty acid methyl ester). O padrão interno (PI) utilizado foi o éster metílico 23:0Me Tricosa-noato de metila, adquirido da Sigma-Aldrich. Este éster foi escolhido como PI por não ter sido identificado como componente da amostra de ésteres produzidos.

\section{RESULTADOS E DISCUSSÃO}

\subsection{Composição dos Ácidos Graxos}

Para ácidos graxos insaturados, observou-se, para o ácido oleico, uma média de 52,47\% e de ácido linoleico uma média de $15,78 \%$, e 4,60\% para o ácido palmitoleico. Quanto para os ácidos graxos saturados, a variação média observada para o ácido palmítico foi $22,10 \%$ e para o ácido esteárico, 1,61\%. Para produção de biodiesel, DUART, et al., (2010) cita que elevados teores de ácidos graxos saturados podem levar a cristalização, devido à temperatura. A Tabela 2 apresenta as percentagens dos ácidos graxos obtidos por cromatografia em fase gasosa a partir do óleo bruto da polpa do fruto de macaúba.

Tabela 1 - Percentagem dos ácidos graxos do óleo da polpa de macaúba

\begin{tabular}{cc}
\hline Ácidos Graxos & Ácidos Graxos (\%) \\
\hline Ácido Palmílico C 16:0 & 22,15 \\
Ácido Palmitoleico C16:1 & 4,60 \\
Ácido Esteárico C 18:0 & 1,61 \\
Ácido Oleico C 18:1n-9 & 52,47 \\
Ácido Linoleico C 18:2n-6 cis & 15,78 \\
Ácido Linolênico C 18:3 & 3,39 \\
\hline
\end{tabular}




\subsection{Obtenção de Ésteres a Partir do Óleo da Polpa de Macaúba}

$\mathrm{Na}$ Tabela 3 são mostrados todos os ensaios conforme a matriz do planejamento experimental $2^{3}$ e os respectivos valores de rendimento para reação de esterificação ácida via rota etílica com óleo da polpa de Macaúba, apresentando alto índice de acidez $(55,21 \mathrm{mg} \mathrm{KOH} / \mathrm{g}$ de amostra).

Tabela 3 - Matriz do planejamento fatorial e os rendimentos obtidos das variáveis para análise da catálise ácida de esterificação do óleo da polpa de Macaúba

\begin{tabular}{cccccccc}
\hline \multirow{2}{*}{ Ensaio } & \multicolumn{5}{c}{ Variáveis } & \multicolumn{5}{c}{ Variáveis Codificadas } & \multirow{2}{*}{$\mathrm{Y} \%$} \\
\cline { 2 - 6 } & Catalisador & $\mathrm{RM}$ & Temperatura $\left({ }^{\circ} \mathrm{C}\right)$ & $\mathrm{X}_{\mathrm{C}}$ & $\mathrm{X}_{\mathrm{R}}$ & $\mathrm{X}_{\mathrm{T}}$ & \\
\hline 1 & 1,3 & $10,38: 1$ & 113,93 & 1 & 1 & 1 & 93,90 \\
2 & 1,3 & $5,62: 1$ & 113,93 & 1 & -1 & 1 & 91,16 \\
3 & 1,3 & $10,38: 1$ & 96,07 & 1 & 1 & -1 & 86,53 \\
4 & 1,3 & $5,62: 1$ & 96,07 & 1 & -1 & -1 & 62,77 \\
5 & 0,7 & $10,38: 1$ & 113,93 & -1 & 1 & 1 & 83,50 \\
6 & 0,7 & $5,62: 1$ & 113,93 & -1 & -1 & 1 & 72,87 \\
7 & 0,7 & $10,38: 1$ & 96,07 & -1 & 1 & -1 & 49,63 \\
8 & 0,7 & $5,62: 1$ & 96,07 & -1 & -1 & -1 & 73,07 \\
9 & 1,5 & $8: 1$ & 105,0 & 1,68 & 0 & 0 & 78,27 \\
10 & 0,5 & $8: 1$ & 105,0 & $-1,68$ & 0 & 0 & 75,23 \\
11 & 1 & $12: 1$ & 105,0 & 0 & 1,68 & 0 & 89,17 \\
12 & 1 & $4: 1$ & 105,0 & 0 & $-1,68$ & 0 & 58,03 \\
13 & 1 & $8: 1$ & 120,0 & 0 & 0 & 1,68 & 81,77 \\
14 & 1 & $8: 1$ & 90,0 & 0 & 0 & -168 & 47,80 \\
15 & 1 & $8: 1$ & 105,0 & 0 & 0 & 0 & 78,27 \\
16 & 1 & $8: 1$ & 105,0 & 0 & 0 & 0 & 79,93 \\
17 & 1 & $8: 1$ & 105,0 & 0 & 0 & 0 & 81,67 \\
\hline
\end{tabular}

Os dados foram analisados usando metodologias estatísticas convencionais (programa Statistic 7.1) e foi obtido o modelo de regressão representado pela Equação 1.

$\mathrm{Y}=79,55+4,45 \mathrm{X}_{\mathrm{C}}+0,11 \mathrm{X}_{\mathrm{c}}{ }^{2}+4,83 \mathrm{X}_{\mathrm{R}}-1,02 \mathrm{X}_{\mathrm{R}}{ }^{2}+9,27 \mathrm{X}_{\mathrm{T}}-4,91 \mathrm{X}_{\mathrm{R}}{ }^{2}+4,91 \mathrm{X}_{\mathrm{C}} \mathrm{X}_{\mathrm{R}}+0,26 \mathrm{XcX}_{\mathrm{T}}+$ $1,62 \mathrm{X}_{\mathrm{R}} \mathrm{X}_{\mathrm{T}}$

O modelo de regressão apresentado na Equação 1 indica que o rendimento em ésteres foi influenciado positivamente pela Temperatura, Catalisador e RM. O efeito da interação entre as variáveis determinada foi positivo, indicando que o aumento da quantidade de álcool utilizada na reação minimiza o efeito negativo causado pelo aumento da temperatura. $O$ coeficiente de 
determinação $\left(\mathrm{R}^{2}\right)$ obtido para este modelo foi de 0,7207 indicando que $72,07 \%$ da variabilidade das respostas podem ser explicados por este modelo.

A análise de variância (ANOVA) dos rendimentos foi realizada para determinar a significância e qualidade do ajuste do modelo quadrático, os efeitos significativos dos termos individuais e as interações no rendimento em ésteres estão apresentados na Tabela 4.

Tabela 4 - Análise de variância (ANOVA) para o rendimento em ésteres obtidos a partir do óleo bruto da polpa de Macaúba

\begin{tabular}{cccccc}
\hline Fonte de Variação & $\begin{array}{c}\text { Grau de } \\
\text { Liberdade }\end{array}$ & $\begin{array}{c}\text { Soma dos } \\
\text { quadrados }\end{array}$ & $\begin{array}{c}\text { Quadrado } \\
\text { Médio }\end{array}$ & $\mathrm{F}_{\text {calc }}$ & $\begin{array}{c}\text { p- } \\
\text { valor }\end{array}$ \\
\hline $\mathrm{X}_{\mathrm{C}(\mathrm{L})}$ & 1 & 806,192 & 806,192 & 12,980 & 0,0008 \\
$\mathrm{X}_{\mathrm{C}(\mathrm{Q})}$ & 1 & 0,432 & 0,432 & 0,00696 & 0,9669 \\
$\mathrm{X}_{\mathrm{R}(\mathrm{L})}$ & 1 & 958,134 & 958,134 & 15,4271 & 0,0003 \\
$\mathrm{X}_{\mathrm{R}(\mathrm{Q})}$ & 1 & 35,267 & 35,267 & 0,56785 & 0,4554 \\
$\mathrm{X}_{\mathrm{T}(\mathrm{L})}$ & 1 & 3518,128 & 3518,158 & 56,6463 & 0,0000 \\
$\mathrm{X}_{\mathrm{T}(\mathrm{Q})}$ & 1 & 580,500 & 580,500 & 9,3468 & 0,0039 \\
$\mathrm{X}_{\mathrm{C}} \mathrm{X}_{\mathrm{R}}$ & 1 & 579,184 & 579,184 & 9,3256 & 0,0039 \\
$\mathrm{X}_{\mathrm{C}}$ & 1 & 1,654 & 1,654 & 0,0266 & 0,8711 \\
$\mathrm{X}_{\mathrm{R}} \mathrm{X}_{\mathrm{T}}$ & 1 & 63,700 & 63,700 & 1,0256 & 0,3171 \\
Erro & 41 & 2546,381 & 62,107 & & \\
Total Corrigido & 50 & 9118,579 & $\mathrm{~F}_{0,05 ; 9,41}=2,129$ & \\
\hline
\end{tabular}

A tabela 4 mostra que para os valores de $\mathrm{F}$ calculados maiores que o valor de $\mathrm{F}$ tabelado $(2,129)$, demonstra que os modelos são estatisticamente significativos ao nível de significância de 95\%. Da mesma maneira, os p-valores são menores do que 5\%, indica também que, os termos quadráticos são estatisticamente significativos no modelo. A partir deste modelo foram construídos o gráfico de superfície de resposta, conforme Figura 2, para que fossem avaliadas as condições em que são obtidos as maiores conversões em ésteres.

O melhor condição encontrada foi no ensaio 1 conforme mostra a Tabela 3, obtendo uma conversão em ésteres de 93,9\%. Nascimento et al., (2010) estudaram a reação de transesterificação a partir do óleo de macaúba com alto índice de acidez, 30\% em ácido oleico e como catalisador enzimático utilizaram Novozin @ 435 e Lipozyme ® TL IM e reportaram uma conversão de 85 e $79 \%$ respectivamente, e observaram que a variável que menos influenciou foi a temperatura e RM etanol:óleo no meio reacional.

A Figura 2(A) mostra o gráfico de Pareto obtido no planejamento experimental, para o rendimento dos ésteres etílicos obtidos a partir do óleo da polpa. 
(A)

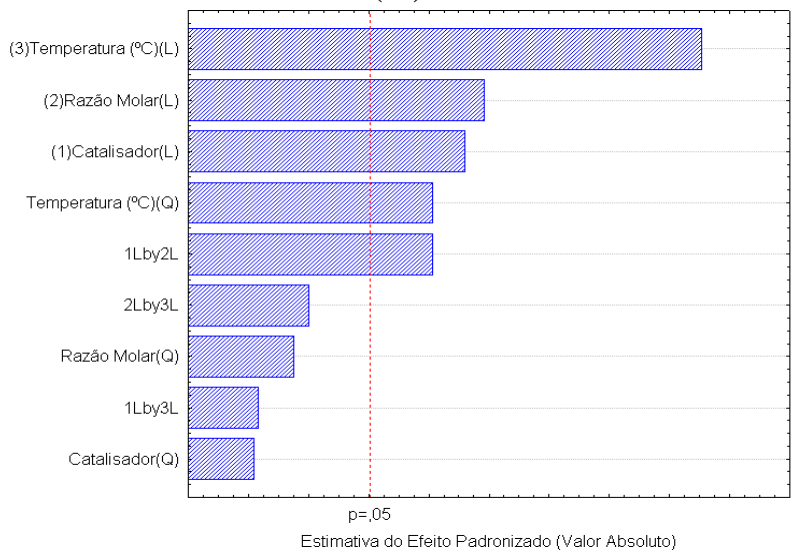

(C)

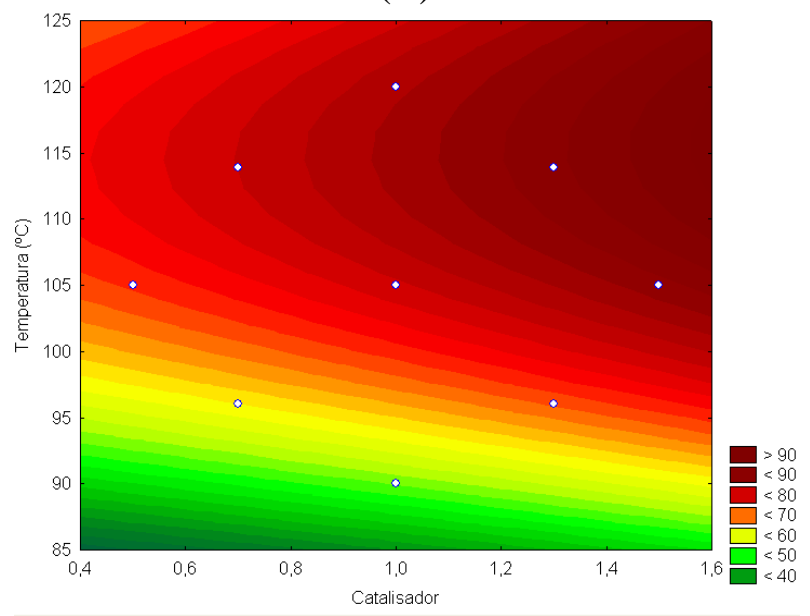

(B)

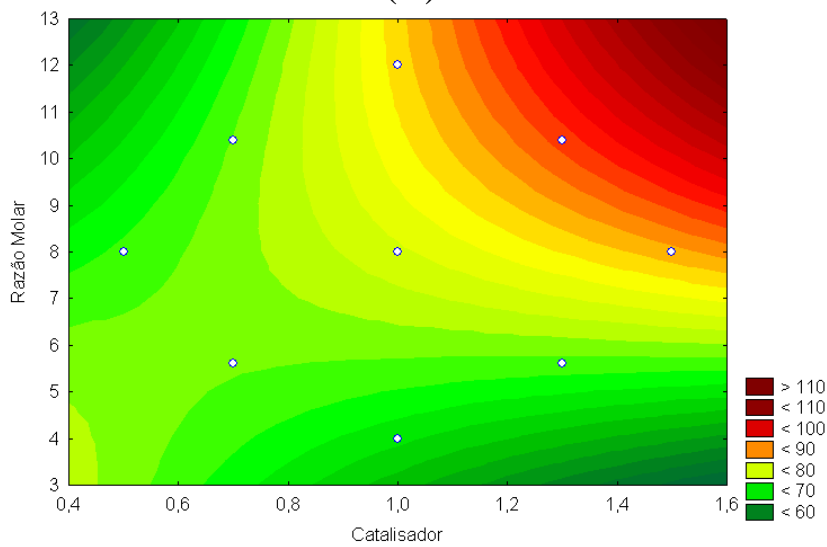

(D)

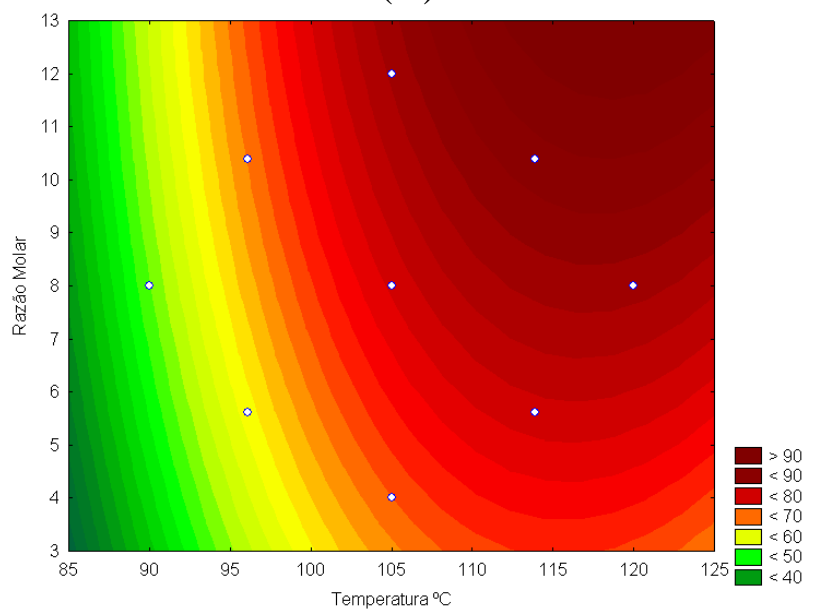

Figura 2 - Gráfico de Pareto resultante do planejamento fatorial $\left(2^{3}\right)$ que avalia os efeitos de cada variável (A). Superfície de resposta para a conversão em ésteres obtidos em função: RM etanol:óleo e catalisador (B); Temperatura e Catalisador (C); RM etanol:óleo e Temperatura (D).

Pode-se verificar que todas as variáveis independentes apresentaram efeitos significativos. Os valores de p-valor menores que 0,05 indicam que os fatores catalisador (1) RM etanol:óleo (2) e temperatura (3) são variáveis estatisticamente significativas a 95\% de confiança. Pode-se observar, também, que a temperatura $(\mathrm{C})$ foi a variável que apresentou maior efeito significativo.

GOMES et al., (2011), avaliaram a influência da temperatura e da RM etanol:óleo na reação de transesterificação alcalina de óleo de soja degomado e canola refinado, utilizaram a um planejamento experimental e hidróxido de sódio como catalisador. A melhor condição encontrada foi na temperatura de $30^{\circ} \mathrm{C}$; RM álcool:óleo de 9:1, conversão em ésteres de $98,7 \%$. Para o óleo de canola refinado foi na temperatura de $45^{\circ} \mathrm{C}$; RM álcool:óleo de 7,5:1, logo a conversão em ésteres foi de $99,8 \%$. 
A condição de processo de esterificação por catálise homogênea ácida via rota etílica para o óleo da polpa de macaúba resultou em maior rendimento utilizando uma RM de 10,38:1 etanol:óleo, uma temperatura de $113,93^{\circ} \mathrm{C}$ e $1,3 \%$ de catalisador. Essas condições estão descritas na Tabela 3.

\title{
4. CONCLUSÃO
}

Na reação de esterificação do óleo bruto da polpa de macaúba com alto índice de acidez $55,21 \mathrm{mgKOH} / \mathrm{g}$ amostra, obteve uma conversão em ésteres etílicos de 93,9\%, sendo este parâmetro apresentou-se abaixo das especificações da ANP, assim sendo necessário realizar uma reação de transesterificação para aumentar a conversão dos ácidos graxos livres presente na amostra que não reagiram durante a reação de esterificação, apresentando um valor de 6,58 $\mathrm{mgKOH} / \mathrm{g}$ amostra. Os resultados apresentados, e os fatores estudados mostra a viabilidade da produção de biodiesel, entre os fatores técnicos estão o rendimento do processo e a pureza do produto, por ser uma matéria prima de baixa qualidade, conclui-se que o óleo bruto da polpa da Macaúba possuem características que viabiliza seu uso como matéria prima para a produção de biodiesel.

\section{AGRADECIMENTOS}

\author{
CAPES \\ Mestrado em Eng. Química - PEQ/UEM \\ Mestrado em Bioenergia - PPB/UEM
}

\section{REFERÊNCIAS}

AOCS; AOCS official method Ca 5a-40: free fatty acids. In Official Methods and Recommended ractices of the AOCS (5 $5^{\text {th }}$ ed.). American Oil Chemists' Society Press, Champaign, IL. (1997).

AZEVEDO FILHO, J. A.; COLOMBO, C. A.; BERTON, L. H. C. Macaúba: palmeira nativa como opção bioenergética. Pesquisa \& Tecnologia, vol. 9, n. 2, Jul-Dez 2012.

BANDEIRA, A. L. Incentivo à pesquisa da macaúba abre novas perspectivas. Maria da Fé. V. $32-$ n. 265. nov/dez. 2011.

CARGNIN, A.; JUNQUEIRA, N. T. V.; FOGAÇA, C. M. Potencial de macaubeira como fonte de matéria-prima para produção de biodiesel. 16 p. Planaltina, DF: Embrapa Cerrados, 2008.

DANTAS, M.B.; ALBUQUERQUE, A.R.; BARROS, A.K.; RODRIGUES FILHO, M.G.; ANTONIOSI FILHO, N.R.; SINFRÔNIO, F.S.M.; ROSENHAIM, R.; SOLEDADE, L.E.B.; SANTOS, I.M.G.; SOUZA, A.G. Evaluation of the oxidativestability of corn biodiesel. Fuel (Guildford), v. 90, p. 773-778, 2011. 
DUART, I. D.; ROGÉRIO, J. B.; ANTONIASSI, R.; BIZZO, H. R.; JUNQUEIRA, N. T. V. Variação da composição de ácidos graxos dos óleos de polpa e amêndoa de macaúba. Congresso Brasileiro de Plantas Oleaginosas, Óleos, Gorduras e Biodiesel. Belo Horizonte - MG. Out. 2010.

MA, F.; HANNA, M. A.; Biodiesel production: a review. Bioresource Technology 70 (1999) 115.

FREEDMAN, B.; PRYDE, E. H.; Mounts, T.L. J. Am. Oil Chem. Soc. 61, 1638. 1984

FORTES, I. C. P., BAUGH, P. J. Study of Analytical On-line Pyrolysis of Oils from Macauba Fruit (Acrocomia sclerocarpa M) via GC/MS. Belo Horizonte, Brazil \& Salford UK. J. Braz. Chem. Soc., Vol. 10, No. 6, 469-477, 1999.

GOMES, M. C. S.; ARROYO, P. A.; PEREIRA, N. C. Biodiesel Production From Degummed Soybean Oil and Glycerol Removal Using Ceramic Membrane. Journal of Membrane Science 378 - 453-461. Maio. 2011

LIM, S.; HOONG, S. S.; TEONG, L. K.; BHATIA, S. Supercritical fluid reactive extraction of Jatropha curcas L. seeds with methanol: A novel biodiesel production method. Bioresource Tecnologia, 2010, Vol. 101, p.7169-7172.

MELO, P. G. Produção e caracterização de biodieseis obtidos a partir da oleaginosa macaúba (Acrocomia aculeata). Dissertação de mestrado - UFU. Uberlandia -MG, 2012.

NASCIMENTO, R. F.; MARIANO R. G. B.; BRIGIDA, A. I. S.; ROCHA-LEÃO, M. H.; FREITAS. S. P.; Produção de biodiesel a partir do óleo ácido de macaúba. $R Q I-2010$.

NUCCI, S. M.; AZEVEDO-FILHO, J. A.; COLOMBO, C. A.; PRIOLLI, R. H. G.; COELHO, R. M.; MATA, T. L.; ZUCCHI, M. I. Development and characterization of microsatellites markers from themacaw. Molecular Ecology Resources (Online) v. 8, p. 224-226, 2008.

PADULA, A. D; SANTOSA, M. S.; FERREIRA, L.; BORENSTEIN, D. The emergence of the biodiesel industry in Brazil: Current figures and future prospects. Energy Policy 44, pag 395405. 2012.

SARKAR, N.; GHOSH, S. K.; BANNERJEE, S.; AIKAT, K. Bioethanol production from agricultural wastes: An overview. West Bengal, India. 2011.

SILVA, G. C. R.; ANDRADE, M. H. C. Development and simulation of a new oil extraction process from fruit of macauba palm tree. J. of Food Process Eng. 36 (2013) 134-145 - 2011. 